\title{
Crude glycerin in co-composting with laying hen manure reduces $\mathbf{N}$ losses
}

\author{
Marco Antonio Previdelli Orrico Junior, Ana Carolina Amorim Orrico*, Aldo Felipe Fava, Natália da Silva Sunada, Alice Watte Schwingel, \\ Rodrigo Garófallo Garcia, Rusbel Raul Aspilcueta Borquis
}

Federal University of Grande Dourados/College of Agricultural Sciences - Dept. of Animal Science, Rod. Dourados - Itahum, km 12 - 79804-970 - Dourados, MS Brazil.

*Corresponding author <anaorrico@ufgd.edu.br>

Edited by: Leônidas Carrijo Azevedo Melo

Received December 01, 2016

Accepted June 02, 2017
ABSTRACT: The composting of laying hen manure is an efficient way of treating waste and producing an organic fertilizer with excellent characteristics; however, the high $\mathrm{N}$ losses reduce its concentration in the resulting fertilizer. Associating this residue with crude glycerin (CG) promotes a better $\mathrm{C}: \mathrm{N}$ ratio and contributes to higher $\mathrm{N}$ retention during composting, with improvements in solids reduction and production of organic fertilizer with higher concentration of this nutrient. We carried out this research considering the hypothesis that adding CG - a byproduct of biodiesel production - to laying hen waste composting provides better $\mathrm{N}$ retention in the fertilizer generated. Increasing CG doses $(0,3,6,9$, and $12 \%$ in relation to the fresh mass in the windrows) were added to the laying hen manure with windrows composted for 70 days. A reduction by $100 \%$ in total and thermotolerant coliforms occurred at all levels of CG addition. The maximum reductions in total (TS) and volatile (VS) solids were 64 and $76 \%$, respectively, and occurred with the addition of $6 \%$ CG. The windrows that did not receive CG had higher N losses during the process (32\%) while the highest $\mathrm{N}$ concentration in the compost was $5 \%$ at $6 \% \mathrm{CG}$. We identified that adding $6 \% \mathrm{CG}$ to the laying hen manure in co-composting increases the reductions in TS and VS and provides higher $\mathrm{N}$ retention, which improves the quality of the organic fertilizer.

Keywords: windrows, total solids, volatile solids

\section{Introduction}

Laying hen manure has large amounts of easily degradable organic material, particularly due to the diets rich in digestible components, high contents of $\mathrm{N}$ and $\mathrm{P}$ and pathogenic microorganisms, such as those of the genera Salmonella and Escherichia (Nadia et al., 2015). Composting is widely employed in egg production facilities and can be defined as an aerobic technique to treat and recycle nutrients in which the organic constituents are broken down until they reach a stable condition thus reducing their polluting traits (Nasiru et al., 2013). This process is able to reduce waste volume, inactivate pathogens, and produce compost, an organic fertilizer (Mehta et al., 2014).

Composting residues in association, also called co-composting, have been previously studied, e.g., by Hachicha et al. (2009) on laying hen manure and olive oil production residue, or by Liu et al. (2015) on laying hen manure and monosodium glutamate. Residue association is based on the higher supply of energy to the medium, such as complementing the $\mathrm{N}$ fraction in the waste, which favors breaking down the material in composting and improving compost quality, e.g., higher nutrient content.

Crude glycerin (CG) stands out as a major agroindustrial residue with high energy content that may be associated with laying hen manure in composting, especially in the central-western region of Brazil, the major biodiesel producer in the country (ANP, 2015), accounting for 1.6 million $\mathrm{m}^{3}$ of the 3.9 million $\mathrm{m}^{3}$ produced nationwide in 2015. The use of laying hen manure is mostly limited by impurities (mainly moisture, lipids, and sodium) that restrict glycerol, which would be the relevant constituent to increase the energy content in the windrows.

One of the main issues when composting laying hen manure is $\mathrm{N}$ loss, since, according to Orrico Jr. et al. (2010), the C:N ratio adjustment must be both quantitative and qualitative for the two fractions to have similar availabilities, releasing $\mathrm{C}$ and $\mathrm{N}$ in synchrony and allowing the microorganisms in the medium to assimilate them. Glycerin has a highly available carbon fraction, thus it can maximize the reductions in solids in composting and reduce $\mathrm{N}$ losses through volatilization.

This research was based on the following hypothesis: adding CG to the composting of laying hen manure leads to better adjustment of the C: $\mathrm{N}$ ratio and greater $\mathrm{N}$ retention in the compost.

\section{Materials and Methods}

The research was carried out in the city of Dourados, Mato Grosso do Sul, Brazil $\left(22^{\circ} 11^{\prime} 55^{\prime \prime}\right.$ S, 54 $56^{\circ} 7^{\prime \prime}$ $\mathrm{W}$ and $452 \mathrm{~m}$ altitude). According to the Köppen classification (Alvares et al., 2013), the climate in the region is humid mesothermal - Cwa, with average temperature and rainfall between 20 and $24{ }^{\circ} \mathrm{C}$ and 1,250 and $1,500 \mathrm{~mm}$, respectively. A completely randomized design was used in the experiment and the experimental treatments were defined by the levels of CG addition 
$(0,3,6,9$, and $12 \%$ in relation to the fresh mass in the windrows) to the manure of Bovans White laying hens with approximately 70 weeks, consisting of six replicates (windrows).

For manure collection, the floor below the hen cages was previously cleaned to remove all residues in the area. On the day of collection, the waste mass accumulated for a maximum period of 7 days was scraped straight from the floor to obtain the amount needed to form the experimental windrows. The waste collected was homogenized and sampled to determine total solids (TS), which was around $45 \%$, thus ensuring a desirable content to form the windrows with no excess or lack of moisture. TS content was used only for the control of the moisture condition in the material since CG was added to the manure as a function of weight of the fresh mass of waste.

The initial composition of the laying hen manure was $45 \%$ TS of which $78 \%$ were volatile solids (VS) and 20 and $3 \%$ were organic carbon and nitrogen, respectively. Crude glycerin had $95 \%$ TS, $14 \%$ glycerol, 6 $\%$ methanol, and $78 \%$ lipids, besides chemical oxygen demand (COD) of 1,532 $\mathrm{g} \mathrm{O}_{2} / \mathrm{L}$ glycerin.

The manure collected was mixed to $\mathrm{CG}$ at the specified doses and each windrow was individually prepared and manually homogenized. This material was stored in cylindrical PVC containers, called microwindrows, $0.25 \mathrm{~m}$ in diameter and $0.5 \mathrm{~m}$ in length, sealed at the bottom and with holes drilled along the length to facilitate measuring the temperature. Each container corresponded to one windrow or experimental unit. Each windrow contained approximately $17 \mathrm{~kg}$ of fresh mass (manure + crude glycerin) in composting and, in order to maintain aerobic process conditions, temperature was controlled daily and TS content, weekly. All the material in each windrow was poured from the PVC container onto a plastic tarp on the ground, homogenized and returned to the container to aerate the interior of the piles. The material was turned every other day for the first 15 days of composting, every 3 days over the next 15 days, and every 5 days in the following fortnight. After this 45day period, the material was turned once a week until the end of the composting process.

The windrows were composted for 70 days and the stabilization of mass loss was used as parameter to determine the end of the process. During the experimental period, the masses and volumes of the windrows were monitored and material was collected to determine $\mathrm{pH}$, TS, VS, C, and their fractioning (compostable organic matter - COM, composting-resistant organic matter - CROM, and COD), besides the most probable numbers (MPNs) of total and thermotolerant coliforms and $\mathrm{N}$ contents.

$\mathrm{N}$ reductions were calculated from the total amounts of solid mass in the windrows and $\mathrm{N}$ concentrations, considering the beginning and end of the composting period, which allows estimating the amount of $\mathrm{N}$ lost during the process.

\section{Methodologies used}

The analyses of TS, VS, total and thermotolerant coliforms, and $\mathrm{pH}$ were performed according to the methodology described by the APHA (2005). The oxidizable organic carbon, compostable organic matter, CROM, and COD were estimated by the methodology described by Kiehl (1985). The N content was assessed as described by Silva and Queiroz (2006). The temperatures were measured daily at 08 h00 a.m. using a rod thermometer inserted at the center of the windrows.

The results underwent analysis of variance and orthogonal contrasts were used to assess the linear, quadratic, and cubic effects on the CG doses. The analyses were performed by the software $\mathrm{R}$, version 3.1.0 for Windows (R core team, 2017).

The principal components analysis (PCA) was used to investigate the relation between the variables monitored and between the variables and the experimental conditions. The principal components (PCs) were extracted from the correlation among the variables of the original matrix to prevent any interference of the measurement units on the variables studied. Enough PCs were selected to explain between 80 and $90 \%$ of the variance in the data (Johnson and Wichern, 2007).

\section{Results and Discussion}

The temperatures during the co-composting of laying hen manure and crude glycerin (Figure 1) were reached similarly among the different levels of glycerin addition, except for the treatment with $12 \%$ glycerin, which resulted in lower temperatures throughout composting. Keeping the temperatures within thermophilic ranges is recommended to inactivate pathogenic microorganisms, besides aiding in breaking down the residues thus increasing the reduction of solid constituents.

The results for MPNs of total and thermotolerant coliforms and reductions of those groups during composting (Table 1) show that the process was effective in obtaining an organic fertilizer that can be used immediately and free of sanitary risks. Besides the temperature at thermophilic conditions for over 2 weeks for the

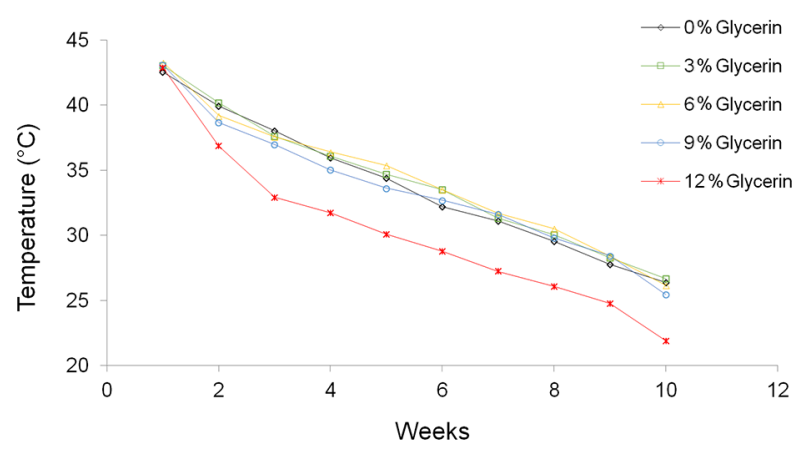

Figure 1 - Average weekly temperatures during the composting of laying hen manure and increasing levels of crude glycerin addition. 
Table 1 - Most probable numbers (MPN/100 g material) of total and thermotolerant coliforms and reductions during the composting of laying hen manure with increasing levels of crude glycerin addition.

\begin{tabular}{|c|c|c|c|c|c|c|c|c|}
\hline \multirow{3}{*}{ Glycerin addition } & \multirow{2}{*}{\multicolumn{3}{|c|}{$\begin{array}{c}\text { Total coliforms } \\
\text { Days of composting }\end{array}$}} & \multirow{3}{*}{ 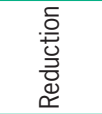 } & \multirow{2}{*}{\multicolumn{3}{|c|}{$\begin{array}{c}\text { Thermotolerant coliforms } \\
\text { Days of composting }\end{array}$}} & \multirow{3}{*}{ 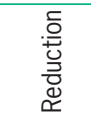 } \\
\hline & & & & & & & & \\
\hline & 0 & 35 & 70 & & 0 & 35 & 70 & \\
\hline$\%$ & & & & $\%$ & & & & $\%$ \\
\hline 0 & $2.58 \mathrm{E}+07$ & $0.21 \mathrm{E}-02$ & 0.00 & 100.00 & $1.87 \mathrm{E}+07$ & $0.00 \mathrm{E}+00$ & 0.00 & 100.00 \\
\hline 3 & $4.15 \mathrm{E}+07$ & $0.60 \mathrm{E}-02$ & 0.00 & 100.00 & $2.85 \mathrm{E}+07$ & $0.12 \mathrm{E}-02$ & 0.00 & 100.00 \\
\hline 6 & $3.40 \mathrm{E}+07$ & $7.38 \mathrm{E}+00$ & 0.00 & 100.00 & $2.09 \mathrm{E}+07$ & $6.00 \mathrm{E}-02$ & 0.00 & 100.00 \\
\hline 9 & $1.59 \mathrm{E}+07$ & $9.88 \mathrm{E}+00$ & 0.00 & 100.00 & $0.78 \mathrm{E}+07$ & $7.22 \mathrm{E}+00$ & 0.00 & 100.00 \\
\hline 12 & $0.20 E+07$ & $2.50 E+02$ & 0.00 & 100.00 & $0.13 \mathrm{E}+07$ & $7.17 \mathrm{E}+00$ & 0.00 & 100.00 \\
\hline
\end{tabular}

windrows added with crude glycerin at 0 to $9 \%$, keeping the $\mathrm{pH}$ in the alkaline range (Figure 2) may also have contributed to the formation of a hostile environment to coliforms. This effect may also have helped in windrows that contained $12 \%$ glycerin since, at 35 days of composting, the reductions in MPNs of total and thermotolerant coliforms had already surpassed $90 \%$ of the initial contents in all windrows.

The effects of temperature and the $\mathrm{pH}$ possibly determined the reduction in coliforms in the windrows and may also have helped actinobacteria break down the organic material. The action of those bacteria is favored when the $\mathrm{pH}$ remains neutral or slightly alkaline (up to 9.0) and the temperature is close to $45^{\circ} \mathrm{C}$ (Diaz et al., 2007). Those microorganisms have high breaking down efficiency and may reach over $40 \%$ reduction in the initial solid fraction during the first 7 days of composting. However, at higher temperatures and the $\mathrm{pH}$ in the alkaline range, large losses of the $\mathrm{N}$ fraction are reported, particularly when it has little resistance to degradation (Wang et al., 2015). The nitrifying and $\mathrm{N}$-fixating groups dominate the microbial population at more advanced stages of the composting process and, initially, the losses of the $\mathrm{N}$ fraction are larger and occur more easily under alkaline $\mathrm{pH}$ conditions (Diaz et al., 2007).

The formation of windrows containing CG in association with laying hen manure was planned aiming to add easily degradable carbon (glycerol) to a source of $\mathrm{N}$ available at higher amounts in an attempt to synchronize the rate of organic constituent break down while maximizing the results of the composting process. However, the source of CG used contained low glycerol levels (only $14 \%$ ) and high concentrations of lipids (close to $78 \%$ ) thus resulting in the inclusion of $2 \%$ lipids in windrows containing $3 \%$ CG glycerin up to $9 \%$ lipids in windrows with $12 \%$ glycerin.

Hachicha et al. (2009) recommended adding lipids to composting windrows up to a concentration of $17 \%$, which improves the thermophilic phase (longer duration and higher temperatures) and the consequent sanitization of the final product. However, under the experimental conditions described by those authors, the wastewater of olive oil extraction was employed as a source of lipids thus representing a by-product with high concentration of unsaturated fatty acids /oleic and

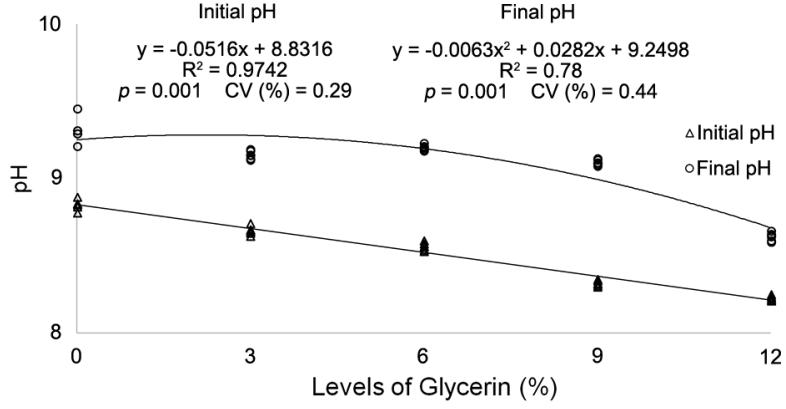

Figure 2 - Initial and final pH values during the composting of laying hen manure and increasing levels of crude glycerin addition.

linoleic) in the degradation medium and lower inclusion of toxic components since this residue is obtained by physically pressing olives with no other constituent added. Moreover, the authors used continuous aeration in the composting piles, which may have raised oxygen availability inside the windrows and favored temperature increases. In the experimental conditions of this research, adding higher doses of glycerin (above $6 \%$ ) favored the formation of denser composting windrows since, although glycerin contains low moisture, it is a liquid residue and favors the clumping of particles in the composting mass, which then reduces the space available to maintain aeration in the piles.

From the results of the reduction in solid constituents, carbon and its fractions, and $\mathrm{N}$, the predictive models were obtained, which were used to estimate the dose of crude glycerin that yielded the best results. These models show that the maximum reductions in TS and VS (Figure 3) occurred when $6 \%$ CG was added to the windrows, reaching 64 and $76 \%$, respectively. These high degradations are likely associated with the easy digestion of the constituents added by CG since the addition at $6 \%$ was higher than that in the control treatment. This amount of glycerin added $1 \%$ glycerol and 4 $\%$ lipids. Possibly, adding glycerin at more than $6 \%$ contributed to reducing aeration in the windrows and thus reduced the intensity of the degradation inside the piles.

The expected reduction in solids during the composting process increases with higher availabilities of the organic constituents for digestion and degradations 
for waste from non-ruminants are higher compared to those obtained in the composting of ruminant waste. When composting exclusively bird manure, Wang et al. (2015) found reductions in VS by $63 \%$ over 60 days of composting, which can be considered an excellent rate, while Orrico Jr. et al. (2012) found maximum values of $44 \%$ for the breakdown of VS over 70 days of composting bovine waste. This way, it can be considered that adding CG to the windrows formed with laying hen manure increased the reductions in VS by up to $22 \%$, favoring the breakdown of organic constituents and pollutants, resulting in better quality organic fertilizer.

$\mathrm{N}$ retention during composting of residues is key for the composting to be considered efficient in recycling nutrients since, along with other relevant components for agriculture such as $\mathrm{P}$ and $\mathrm{K}$, it determines the quality of the organic fertilizer. This concern has been reported for years as essential (Eiland et al., 2001; Tiquia and Tam, 2002), since this residue has the required conditions for high $\mathrm{N}$ losses with alkaline $\mathrm{pH}$, intense initial thermophilic phase, and ammonia formation, which is easily lost through volatilization and steals $\mathrm{N}$ from the composting mass. The acidification of the medium is an alternative that may prevent undesirable $\mathrm{N}$ losses and reduce the emission of odors with the formation of ammonia from composting of laying hen waste. In pre-

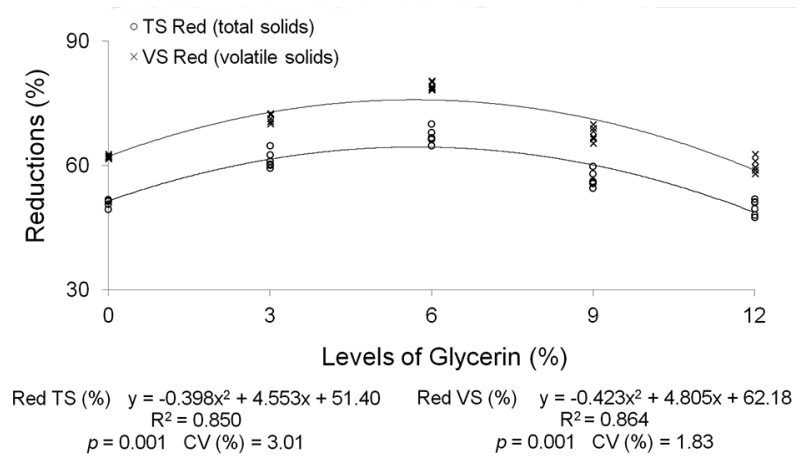

Figure 3 - Total solids (TS) and volatile solids (VS) reductions during the composting of laying hen manure and increasing levels of crude glycerin addition. vious studies, Mari et al. (2005) used sulfuric acid, Yu and Huang (2009) used sodium acetate, and Jeong and Kim (2001) used phosphoric acid, techniques that are effective in achieving greater $\mathrm{N}$ retention during composting; however, they do not necessarily contribute to increasing the availability of the organic fraction for breakdown. The results for $\mathrm{N}$ losses (Figure 4) show that CG was efficient in retaining $\mathrm{N}$ during composting since the losses decreased as CG was added to the windrows and the composting condition with no-glycerin added resulted in the largest loss during the process (32\%), which was $30 \%$ higher than the losses $(22 \%)$ observed at the maximum CG inclusion of $12 \%$. The results of $\mathrm{N}$ losses (Figure 4 and Table 2) allow interpreting that CG was efficiently retained during composting since losses decreased as CG was added to the windrows and that the composting with no CG added had the highest losses over the process (32\%, or a loss index of $100 \%$ ). Another key complementary result to indicate that the addition of CG to the composting of laying hen manure is that $\mathrm{N}$ concentration in the compost (Figure 5) peaked when $6 \%$ CG was added, reaching $5 \% \mathrm{~N}$, while the $\mathrm{N}$ content in the compost with no $\mathrm{CG}$ added was $3 \%$ (36\% lower). The $\mathrm{N}$ content in the starting material decreased as glycerin was added, i.e., the higher contents (3\%) were obtained for the treatment with no glycerin

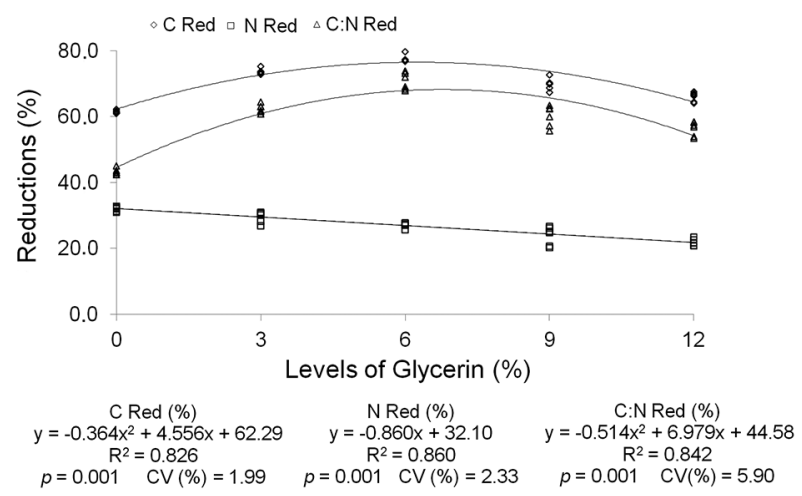

Figure 4 - Reductions in carbon, nitrogen, and $\mathrm{C}: \mathrm{N}$ ratio during the composting of laying hen manure and increasing levels of crude glycerin addition.

Table 2 - Total solids mass (kg), C: $\mathrm{N}$ ratio, contents (\%), amounts (kg), reductions, and relative loss of $\mathrm{N}$ during composting of laying hen manure and increasing crude glycerin addition levels.

\begin{tabular}{|c|c|c|c|c|c|c|c|c|c|c|}
\hline \multirow{2}{*}{ Glycerin Addition } & \multicolumn{2}{|c|}{$\mathrm{N}$} & \multicolumn{2}{|c|}{ TS } & \multicolumn{2}{|c|}{$\mathrm{N}$} & \multirow{2}{*}{ Red N } & \multirow{2}{*}{$\begin{array}{l}\text { Relative N } \\
\text { loss }^{*}\end{array}$} & \multicolumn{2}{|c|}{ C:N Ratio } \\
\hline & in & co & in & co & in & co & & & in & co \\
\hline & & & & & & 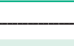 & 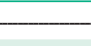 & 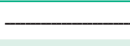 & & \\
\hline 0 & 2.47 & 3.43 & 8.02 & 3.93 & 0.20 & 0.13 & 32.02 & 100.00 & 7.91 & 4.49 \\
\hline 3 & 2.42 & 4.40 & 8.36 & 3.23 & 0.20 & 0.14 & 29.64 & 91.36 & 8.61 & 3.23 \\
\hline 6 & 2.26 & 5.01 & 8.69 & 2.86 & 0.20 & 0.14 & 27.13 & 84.73 & 9.65 & 2.82 \\
\hline 9 & 2.25 & 3.95 & 8.13 & 3.51 & 0.18 & 0.14 & 23.99 & 74.82 & 10.66 & 4.23 \\
\hline 12 & 2.18 & 3.40 & 8.68 & 4.35 & 0.19 & 0.15 & 21.93 & 68.48 & 11.68 & 5.09 \\
\hline
\end{tabular}

TS in = total solids contained in the initial material; $\mathrm{TS} \mathrm{co}=$ total solids contained in the compost; $\mathrm{N}$ in $=\mathrm{N}$ contained in the initial material; $\mathrm{N}$ co $=\mathrm{N}$ contained in the compost; Red N = Reduction in N; *Relative N loss = Corresponds to the reduction in N during the composting process, with the values obtained in the control group considered the maximum loss (100 \%); C:N ratio = carbon:nitrogen ratio. 
added. Nonetheless, since the losses were higher during composting, the resulting composts had the lowest $\mathrm{N}$ concentrations. The relative $\mathrm{N}$ losses (Table 2) reflect a better $\mathrm{N}$ retention during composting when $\mathrm{CG}$ is added, which is seen in all experimental treatments, with the lowest values referring to the maximum $\mathrm{N}$ inclusion (68\% compared to the control group). This index was suggested to assess the results to highlight the benefit of adding CG at any level on $\mathrm{N}$ retention. However, mass losses (represented by the reductions in TS and VS) are also indicative of the efficiency in breaking down the material in the composting and that the data obtained in this study show decreasing reductions starting at $6 \%$ glycerin addition.

The composting conditions ( $\mathrm{pH}$ and temperature), particularly at the beginning of the process, were favorable to higher $\mathrm{N}$ losses. Kithome et al. (1999) considered that up to $62 \%$ of the initial $\mathrm{N}$ in windrows formed by laying hen manure could be easily lost as ammonia during the first 15 days of composting. Liu et al. (2015) assessed the use of wastewater from monosodium glutamate production aiming to reduce this unfavorable condition for $\mathrm{N}$ retention and recommended adding up to $3 \%$ glutamate to the windrows formed by bird waste, which reduced ammonia volatilization by $71 \%$ in the first 10 days of composting. Monosodium glutamate wastewater contains, besides proteins and free amino acids, high amounts of easily degradable carbon, which the authors reported as the most important component to reduce $\mathrm{N}$ losses, a behavior that can be compared to the action of CG in the windrows. Despite the good results of adding glutamate residue on $\mathrm{N}$ retention, it is important to take into account the regional supply of byproducts that can be associated with laying hen manure. The context in which this study was developed presents a large amount of biodiesel produced in the central-western region of Brazil and the presence of egg farms stand out.

The reductions of carbon and its fractions also represent the intensity of breaking down of the organic

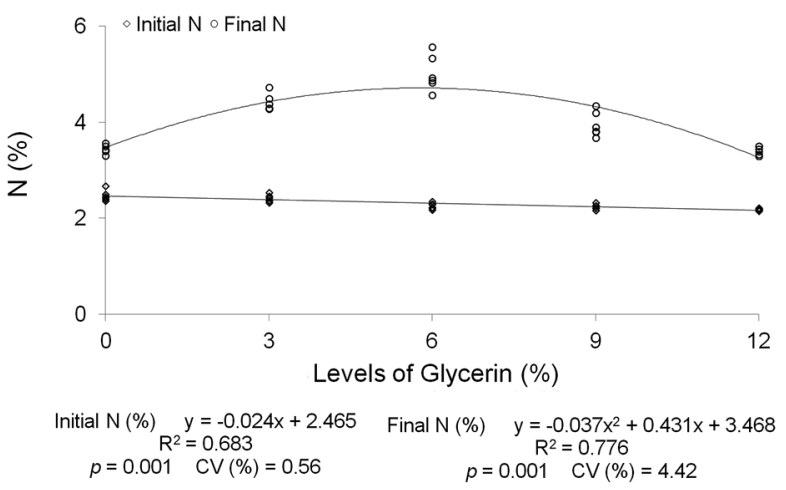

Figure 5 - $\mathrm{N}$ contents (\%) in the initial and final material of the composting of laying hen manure and increasing levels of crude glycerin addition. material and the ease of those processes, while the ease of breaking down of the $\mathrm{C}$ fraction provided by $\mathrm{CG}$ addition may have quickly reached mineralization, thus, immobilizing $\mathrm{N}$ in the windrows $(0.94$ correlation for $\mathrm{C}$ reduction and $\mathrm{N}$ retention), as reported by Diaz et al. (2007). The more similar the reductions in COM and CROM, the lower the resistance to digestion of the residues. Therefore, it can be seen that the maximum reductions in COM and CROM 177 and $75 \%$, respectively, Figure 6) were high and had similar values; however, they occurred with different glycerin additions, at $6 \%$ for COM and $5 \%$ for CROM. It is likely that, as crude glycerin is added at higher doses and aeration is possibly compromised inside the piles, the oxidation of the composting-resistant fraction was hindered, resulting in higher degradation intensity at lower glycerin addition levels.

Orrico Jr. et al. (2012) obtained reductions by 75 and $72 \%$ for the COM contained in composting windrows composed of waste from beef cattle fed diets containing 60 and $40 \%$ concentrate, respectively, while the reductions in CROM in those same conditions were by only 53 and $38 \%$, respectively. This behavior highlights the easy breakdown of the organic constituents of laying hen manure during composting, in particular when in association with CG.

The behavior observed for the reductions in solids, especially the volatile fraction, was similar to carbon reductions and the $\mathrm{C}: \mathrm{N}$ ratio, with the maximum values found when 6 and $7 \%$ CG were added, reaching reductions by 77 and $68 \%$ for $\mathrm{C}$ and the $\mathrm{C}: \mathrm{N}$ ratio, respectively. These high values show the benefits of using glycerin in association with laying hen manure. They also indicate the potential of these mixtures effectively broken down by the composting process since the higher the reduction in organic material in the compost, the better its quality.

The COD reductions (Figure 6) express the loss of polluting capacity of the residues and are a measure used as a parameter for the efficiency of the compost-

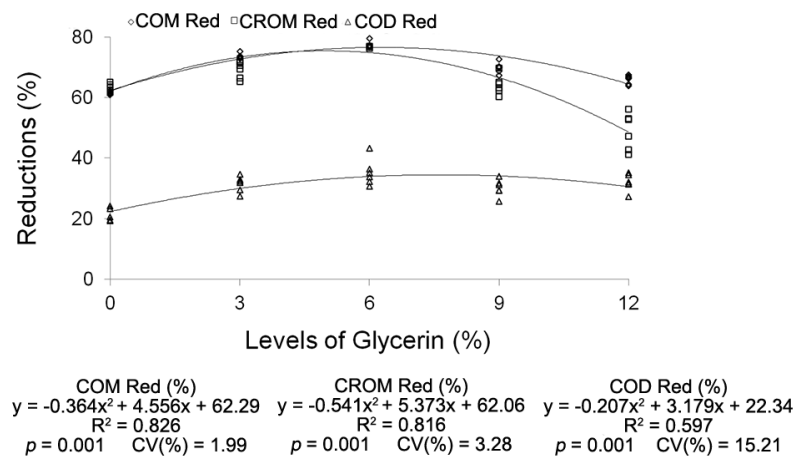

Figure 6 - Reductions in compostable organic matter (COM), composting-resistant organic matter (CROM), and chemical oxygen demand (COD) during the composting of laying hen manure and increasing levels of crude glycerin addition. 
ing in treating residues. The values observed indicate maximum reduction by $35 \%$ when $8 \%$ crude glycerin is added, resulting in COD of $356 \mathrm{~g}$ per $\mathrm{kg}$ of compost, which is considered safe for use as mentioned by Kiehl (1985).

The linear correlation coefficients among the variables are presented in Table 3. The correlations among the variables related to the reduction in solid and organic constituents were moderate to high, which shows the interdependence among them. According to the recommendation by Costa et al. (2015), PCA must be applied in this situation. In the present study, the principal components 1 and 2 alone explained $91 \%$ of the variation in data.

Principal component 1 (PC1) explains $57 \%$ of the variation and relates the variables of reductions in $\mathrm{TS}$, VS, C, COM, CROM, and the C:N ratio, besides the final $\mathrm{N}$ content (positively correlated) as responsible for those results. PC1 may be used as an index to direct the best composting performance of laying hen waste with the use of CG. Those results suggest that the best composting process occurs when CG is added to a medium dose (around $6 \%$, as verified with the use of predictive models), which results in higher $\mathrm{N}$ concentration in the compost. Treatments 2 and 3 (3 and $6 \%$ crude glycerin addition, Figure 7) positively contributed to PC1. Treatments with CG added are distributed in a related manner, while the treatment without glycerin is far and isolated.

The variables of initial and final $\mathrm{pH}, \mathrm{N}$ reduction, and initial $\mathrm{N}$ are related in principal component 2 (PC2) and explain $35 \%$ of the variation (Figure 7$)$. The initial $\mathrm{pH}$ and reduction in $\mathrm{N}$ had the highest dependence correlation (0.92, Table 3), which confirms that lower $\mathrm{pH}$ values resulted in lower $\mathrm{N}$ losses.

Crude glycerin represents an important tool to help in the breakdown of animal production waste, besides providing conditions for higher $\mathrm{N}$ contents in the

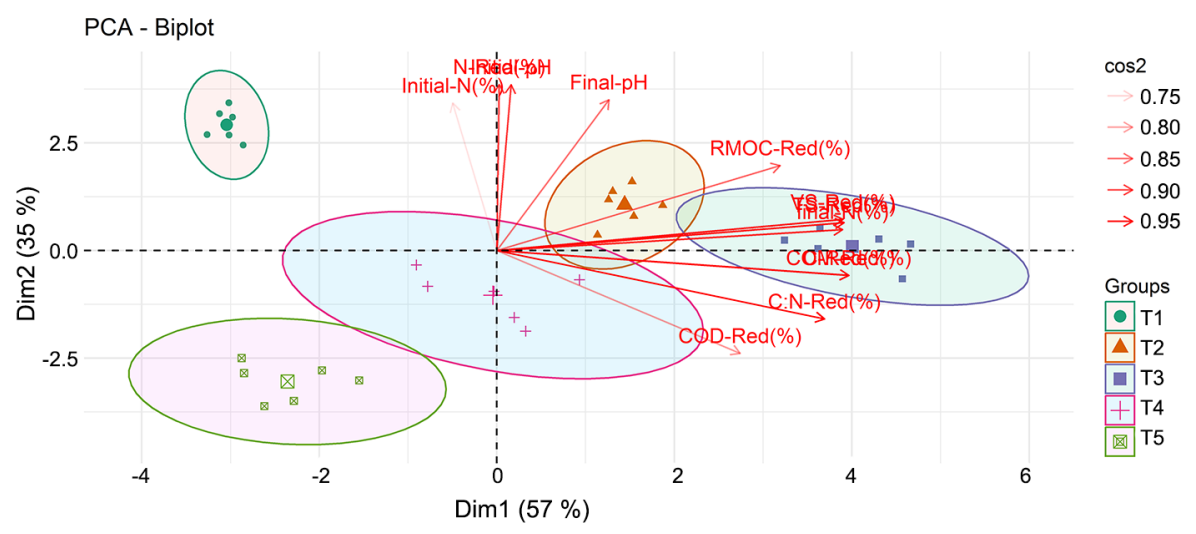

Figure 7 - Biplot of the principal component analysis (PCA) for the variation in parameters during the composting of windrows containing laying hen manure added with crude glycerin. T1 = $0 \%$ crude glycerin; T2 = $3 \%$ crude glycerin; T3 = $6 \%$ crude glycerin; T4 = $9 \%$ crude glycerin; and $\mathrm{T} 5=12 \%$ crude glycerin.

Table 3 - Linear correlation among the different variables assessed during the co-composting of crude glycerin and laying hen manure.

\begin{tabular}{|c|c|c|c|c|c|c|c|c|c|c|c|c|}
\hline & TS Red & VS Red & C Red & N Red & C:N Red & COM Red & CROM Red & COD Red & Initial pH & Final $\mathrm{pH}$ & Initial N & Final $\mathrm{N}$ \\
\hline & & & & $-\%$ & & & & & & & \multicolumn{2}{|c|}{ - $\%$} \\
\hline TS Red (\%) & 1 & $0.96^{\star \star \star}$ & $0.93^{* \star *}$ & $0.17 \mathrm{~ns}$ & $0.83^{* \star *}$ & $0.93^{* \star *}$ & $0.83^{* * *}$ & $0.50^{* *}$ & $0.18 \mathrm{~ns}$ & $0.44^{*}$ & $-0.02 \mathrm{~ns}$ & $0.98^{* * *}$ \\
\hline VS Red (\%) & & 1 & $0.91^{* * *}$ & $0.18 \mathrm{~ns}$ & $0.80^{* * *}$ & $0.91^{* * *}$ & $0.91^{\text {** * }}$ & $0.52^{* *}$ & $0.20 \mathrm{~ns}$ & $0.47^{* *}$ & $-0.02 n s$ & $0.93^{* * *}$ \\
\hline C Red (\%) & & & 1 & -0.11 & $0.96^{* * *}$ & $0.99^{* * *}$ & $0.67^{* * *}$ & $0.78^{* * *}$ & -0.09 & $0.16 \mathrm{~ns}$ & $-0.21 \mathrm{~ns}$ & $0.94^{* * *}$ \\
\hline N Red (\%) & & & & 1 & $-0.37^{\star}$ & $-0.11 \mathrm{~ns}$ & $0.42^{*}$ & $-0.52^{* *}$ & $0.92^{* * *}$ & $0.77^{* * *}$ & $0.84^{* * *}$ & $0.12 \mathrm{~ns}$ \\
\hline C:N Red (\%) & & & & & 1 & $0.96^{\star * *}$ & $0.51^{\star *}$ & $0.87^{* * *}$ & -0.33 ns & $-0.06 \mathrm{~ns}$ & $-0.42^{*}$ & $0.84^{* \star *}$ \\
\hline COM Red (\%) & & & & & & 1 & $0.67^{* * *}$ & $0.78^{* * *}$ & $-0.09 \mathrm{~ns}$ & $0.16 \mathrm{~ns}$ & $-0.21 \mathrm{~ns}$ & $0.94^{* * *}$ \\
\hline CROM Red (\%) & & & & & & & 1 & $0.19 \mathrm{~ns}$ & $0.47^{\star *}$ & $0.72^{* *}$ & $0.22 \mathrm{~ns}$ & $0.78^{* * *}$ \\
\hline COD Red (\%) & & & & & & & & 1 & $-0.49^{* *}$ & $-0.35 \mathrm{~ns}$ & $-0.44^{*}$ & $0.56^{* *}$ \\
\hline Initial pH & & & & & & & & & 1 & $0.80^{* * *}$ & $0.80^{* \star *}$ & $0.15 \mathrm{~ns}$ \\
\hline Final pH & & & & & & & & & & 1 & $0.60^{* * *}$ & $0.38^{*}$ \\
\hline Initial N(\%) & & & & & & & & & & & 1 & $0.02 \mathrm{~ns}$ \\
\hline Final N(\%) & & & & & & & & & & & & 1 \\
\hline
\end{tabular}

${ }^{* \star *} p<0.001 ;{ }^{* *} p<0.01 ;{ }^{*} p<0.05 ; \mathrm{ns}=$ non-significant; TS Red $=$ Total solids reduction; VS Red = Volatile solids reduction; $\mathrm{C}$ Red = carbon reduction; $\mathrm{N}$ Red $=$ nitrogen reduction; C:N Red $=\mathrm{C}: \mathrm{N}$ ratio reduction; $\mathrm{COM}$ Red = compostable organic matter reduction; CROM Red = composting-resistant organic matter reduction; COD Red = chemical oxygen demand reduction. 
compost. Its beneficial effects have already been proven in anaerobic reactors, as reported by Orrico Jr. et al. (2016) and Haitl et al. (2012), who used glycerin in the substrates and found greater breakdown of the solids contents during the digestion process, besides higher biogas and methane productions. Nonetheless, few studies are available on composting.

\section{Conclusions}

Adding $6 \%$ crude glycerin to laying hen manure improves the composting process, increasing the reductions in total and volatile solids and allowing for higher $\mathrm{N}$ retention in the compost.

\section{Acknowledgements}

This research was carried out with the financial support of the Federal University of Grande Dourados (UFGD) and of the Foundation for the Support to the Development of Teaching, Science and Technology of the state of Mato Grosso do Sul (Fundect), besides the Master's degree scholarship provided by the Coordination for the Improvement of Higher Level Personnel (CAPES).

\section{References}

Agência Nacional do Petróleo [ANP]. 2015. Brazilian statistical yearbook of petroleum, natural gas and biofuels = Anuário estatístico Brasileiro do petróleo, gás natural e biocombustíveis. Available at: http://www.anp.gov.br [Accessed Oct 16, 2016] (in Portuguese).

Alvares, C.A.; Stape, J.L.; Sentelhas, P.C.; Gonçalves, J.L.M; Sparovek, G. 2013. Köppen's climate classification map for Brazil. Meteorologische Zeitschrift 22: 711-728.

American Public Health Association [APHA]. 2005. Standard Methods for Examination of Water and Wastewater. 21ed. American Water Works Association, Washington, DC, USA.

Costa, M.S.S.M.; Cestonaro, T.; Costa, L.A.M.; Rozatti, M.A.T.; Carneiro, L.J.; Pereira, D.C.; Lorin, H.E.F. 2015. Improving the nutrient content of sheep bedding compost by adding cattle manure. Journal of Cleaner Production 86: 9-14.

Diaz, L.F.; Bertoldi, M.; Bidlingmaier, W.; Stentiford, E. 2007. Compost Science and Technology. Elsevier Science, Amsterdam, The Netherlands. (Waste Management Series, 8).

Eiland, F.; Leth, M.; Klamer, M.; Lind, A.M.; Jensen, H.E.K.; Iversen, J.J.L. 2001. $\mathrm{C}$ and $\mathrm{N}$ turnover and lignocellulose degradation during composting of Miscanthus straw and liquid pig manure. Compost Science \& Utilization 9: 186-196.

Hachicha, R.; Hachicha, S.; Trabelsi, I.; Woodward, S.; Mechichi, T. 2009. Evolution of the fatty fraction during co-composting of olive oil industry wastes animal manure: maturity assessment of the end product. Chemosphere 75: 1382-1386.

Haitl, M.; Vítěz, T.; Koutný, T.; Kukla, R.; Lošák, T.; Gaduš, J. 2012. Use of G-phase for biogas production. Acta Universitatis Agriculturae et Silviculturae Mendelianae Brunensis 60: 89-95.
Jeong, Y.K.; Kim, J.S. 2001. A new method for conservation of nitrogen in aerobic composting processes. Bioresource Technology 79: 129-133.

Johnson, R.A.; Wichern, D.W. 2007. Applied Multivariate Statistical Analysis. 6ed. Prentice-Hall, Upper Saddle River, NJ, USA.

Kiehl, E.J. 1985. Organic Fertilizers. = Fertilizantes Orgânicos. Agronômica Ceres, São Paulo, SP, Brazil (in Portuguese).

Kithome, M.; Paul, J.W.; Bomke, A.A. 1999. Reducing nitrogen losses during simulated composting of poultry manure using adsorbents or chemical amendments. Journal of Environmental Quality 28: 194-201.

Liu, L.; Kong, H.; Lu, B.; Wang, J.; Xie, Y.; Fang, P. 2015. The use of concentrated monosodium glutamate wastewater as a conditioning agent for adjusting acidity and minimizing ammonia volatilization in livestock manure composting. Journal of Environmental Management 161: 131-136.

Mari, I.; Ehaliotis, C.; Kotsou, M.; Chatzipavlidis, I.; Georgakakis, D. 2005. Use of sulfur to control $\mathrm{pH}$ in composts derived from olive processing by-products. Compost Science \& Utilization 13: 281-287.

Mehta, C.M.; Uma, P.; Franke-Whittle, I.H.; Sharma, A.K. 2014. Compost: its role mechanism and impact on reducing soil-borne plant diseases. Waste Management 34: 607-622.

Nadia, O.F.; Xiang, L.Y.; Lie, L.Y.; Anuar, D.C.; Afandi, M.P.M.; Baharuddin, S.A. 2015. Investigation of physico-chemical properties and microbial community during poultry manure co-composting process. Journal of Environmental Science 28: 81-94.

Nasiru, A.; Ismail, N.; Ibrahim, M.H. 2013. Vermicomposting: tool for sustainable ruminant manure management. Journal of Waste Management 2013: Article ID 732759.

Orrico Junior, M.A.P.; Orrico, A.C.A.; Lucas Júnior, J. 2010. Waste composting of poultry production: poultry litter and carcass. Engenharia Agrícola 30: 538-545 (in Portuguese, with abstract in English).

Orrico Junior, M.A.P.; Orrico, A.C.A.; Lucas, J.; Sampaio, A.A.M.; Fernandes, A.R.M.; Oliveira, E.A. 2012. Composting of beef cattle manure: influence of period, genotype and diet. Revista Brasileira de Zootecnia 41: 1301-1307 (in Portuguese, with abstract in English).

Orrico Junior, M.A.P.; Schwingel, A.W.; Centurion, S.R.; Orrico, A.C.A. 2016. Co-digestion of swine excreta associated with increasing levels of crude glycerin. Revista Brasileira de Zootecnia 45: 101-106.

Silva, D.J.; Queiroz, A.C. 2006. Food Analysis: Chemical and Biological Methods = Análise de Alimentos: Métodos Químicos e Biológicos. 3ed. Editora Universitária, Viçosa, MG, Brazil (in Portuguese).

Tiquia, S.M.; Tam, N.F.Y. 2000. Characterization and composting of poultry litter in forced-aeration piles. Process Biochemistry 37: 869-880.

Wang, K.; He, C.; You, S.; Weijie, L.; Wang, W.; Zhang, R.; Qi, H.; Ren, N. 2015. Transformation of organic matter s in animal wastes during composting. Journal of Hazardous Materials 300: 745-753.

Yu, H.; Huang, G.K. 2009. Effects of sodium acetate as a pH control amendment on the composting of food waste. Bioresource Technology 100: 2005-2011. 